\title{
Vascularized Organoids: A More Complete Model
}

\author{
Jin $\mathrm{Yu}$ \\ Department of Oncology, Affiliated Zhongshan Hospital of Dalian University, Dalian, China
}

As an emerging research model in vitro, organoids have achieved major progress in recapitulating morphological aspects of organs and personalized precision therapy. Various organoids have been currently constructed in vitro (e.g., brain, heart, liver, and gastrointestinal). Though there are prominent advantages on microstructures and partial functions, most of them have been encountering a frustrating challenge that stromal components (e.g., blood vessels) are in short supplement, which has imposed the main dilemma on the application of such model ex vivo. As advanced technologies, co-culturing pluripotent stem cells, mesenchymal stem cells, with endothelial cells on 3D substrate matrix, are leaping forward, a novel model of an organoid with vascularization is formed. The mentioned contribute to the construction of the functional organoids derived from corresponding tissues, making them more reliable in stem cell research and clinical medicine. The present study overall summarizes progress of the evolution, applications and prospects of vascularized organoids.

Keywords: Vascular organoids, Pluripotent stem cells, Translational medicine, Applications

\section{Introduction}

The organoid is constructed ex vivo by complying with the developmental procedures in vivo, enabling the microstructure of morphology and characteristic to accurately reflect the corresponding organ (1). In addition, the data is more reliable than that of cells, expenditures on cultivation are less, and no ethical problem with the use of animals is involved. Therefore, it is more conducive to studying unique physiological processes and disease occurrence in individuals as compared with cells and animals

Received: September 14, 2020, Revised: November 1, 2020, Accepted: November 30, 2020, Published online: December 31, 2020 Correspondence to Jin Yu

Department of Oncology, Affiliated Zhongshan Hospital of Dalian University, No. 6 Jiefang Street, Dalian 116001, China

Tel: +86-18742591860, Fax: +86-0411-87650211

E-mail: 2947665040@qq.com

(c) This is an open-access article distributed under the terms of the Creative Commons Attribution Non-Commercial License (http://creativecommons.org/ licenses/by-nc/4.0/), which permits unrestricted non-commercial use, distribution, and reproduction in any medium, provided the original work is properly cited.

Copyright (C) 2021 by the Korean Society for Stem Cell Research
(2). However, it is revealed that the generation of the various rare organoids (e.g., pituitary epithelium organoids and the cerebrum organoids) and even the reproductive system (e.g., the prostate) is epoch making. Numerous organoids are generated by merely inducing a mass, which is either ectodermal or endodermal. However, the stroma is located at the mesoderm, especially including vascular endothelial cells (3). As suggested from animal studies, endothelial cells constitute the inner wall of blood vessels for delivery of nutrients and oxygen, as well as establishing an instructive interface that stimulates organogenesis and regeneration by releasing the hormone (4).

It is generally known that the interaction of compartments (e.g., mesenchyme, epithelium, and blood vessels), collectively promoting parenchymal and stromal cells, cross-communicate via signal transduction to trigger integral functions and facilitate maturation of organs (1). Vascular networks, exhibiting crossing arrangements in vivo, aim to ensure that the distance between cells and the source of supplements does not exceed $1 \mathrm{~mm}$, as an attempt to confirm that cells are capable of surviving in an area of 1 3 $\mathrm{mm}$ away from oxygen and nutrients (5).

Overall, it is the endothelial cells involved in the exist- 
ing organoid models that are conducive to composing a functional communication niche, which may drive maturation and exhibit the physiological function comprehensively. This to some extent narrows the gap of the original tissue. Since morphogenetic changes are determined by the exquisite orchestration between the endodermal epithelial, mesenchymal and endothelial progenitors before blood perfusion, it is less likely to generate a well-vascularized organoid in vitro. Above all, the mentioned characteristics limit their applications with respect to clinical transplantation and regenerative medicine. For these reasons, this study first stresses the limitations of general organoids, followed by the evolution of organoids with blood perfusion; then, the phenotypic markers are demonstrated. In brief, this study aims at applications in as many organoids as possible. Lastly, a few perspectives are proposed to study in the future and discuss the vital importance of vascular organoids.

\section{The Limitations of Organoids without Blood Perfusion}

Most of organoids derive from ectodermal or endodermal epithelial progenitors, exclusively composed of endothelial cells or cell types derived from the mesoderm. Inevitably, there is a negotiation for the deficiency of a mesenchymal niche, thereby leading to a hurdle of maturation and function, a common barrier in organoid technologies and tissue engineering $(2,3)$. Thus far, limitations on organoids lacking blood flow have appeared frequently. Therefore, this study illustrates the organoids without blood perfusion from the ectoderm and endoderm below.

\section{The Organoids from the Ectoderm}

It is known that the ectoderm primarily forms the epidermis and nervous system. Yet there are some organoids, especially, the nervous system with slight functions to some extent. For instance, Eiraku et al. (6) demonstrated that an optic cup structure was capable of self-forming a fully stratified structure on a three-dimensional culture. However, the photoreceptors were not functional as impacted by vasculature not presenting in this self-formation phrase. Subsequently, Lancaster et al. (7) set up the cerebral organoids. In addition, though there was recapitulation of the characteristic progenitor zone with abundant outer radial glial stem cells, partial features failed to appear fully (e.g., cortical plate layers forming later under the lack of blood vessels). Besides, Muguruma et al. (8) generated a polarized structure of the cerebellum, whereas they could not form a long-time culture system without blood flow. Sakaguchi et al. (9) formed the functional hippocampal granule and pyramidal-like neurons, whereas they failed to form mature neurons and the hippocampal as impacted by the limitation of blood vessels to deliver the nutrients.

\section{The Organoids from the Endoderm}

In accordance with the ectoderm, the endoderm is associated with numerous organoids (e.g., the lung, which induces the airway epithelial cells to generate organoids). However, there were only a third of the cells' airway epithelia markers. Furthermore, markers of the alveolar airways were expressed early in culture, whereas they were lost later because the vascular endothelium should induce a branching-like program of isolated airway epithelium in cultures $(10,11)$. Dianat et al. (12) induced the generation of cholangiocyte organoids; according to their expectation, the phenotype of differentiation and functional aspects was closer to the naive microcosmic structure of bile duct for the lack of blood vessel. Ogawa et al. (13) co-cultured the cholangiocyte with endothelial cells and subsequently transplanted the microstructure in mice; afterwards, they formed the mature biliary tract organoids, which were biliary signaling pathways activated by stromal elements.

\section{The Progress of Vascular Organoids}

In 2009, Sato et al. (14) combined the isolation of specific adult stem cell populations termed as the leucine-rich repeat that contained G-protein-coupled receptor 5 as intestinal stem cell-specific marker with three-dimensional culture technology, which built crypt-villus structures in vitro. They also introduced a novel model termed as the organoids. Nowadays, there are various organoids from different tissues and organs (Fig. 1), whereas they are adopted to mimic the phenotypes mainly instead of functional applications owing to the lack of angiogenesis. With cultural system improvement, blood vessels are involved in organoids to compose a more harmonious melody. We can appreciate the journey from 2010. Baptista et al. (15) implanted the vascular network scaffold into the liver of mice, in which there was a position that endothelial cells aggregated as observed under the microscope. Apparently, the typical vascular endothelium and liver epithelium could be seen, which is the first successful construction of a bioengineered liver that has advanced the transformation of the medical field. In 2012, Quint et al. (16) 


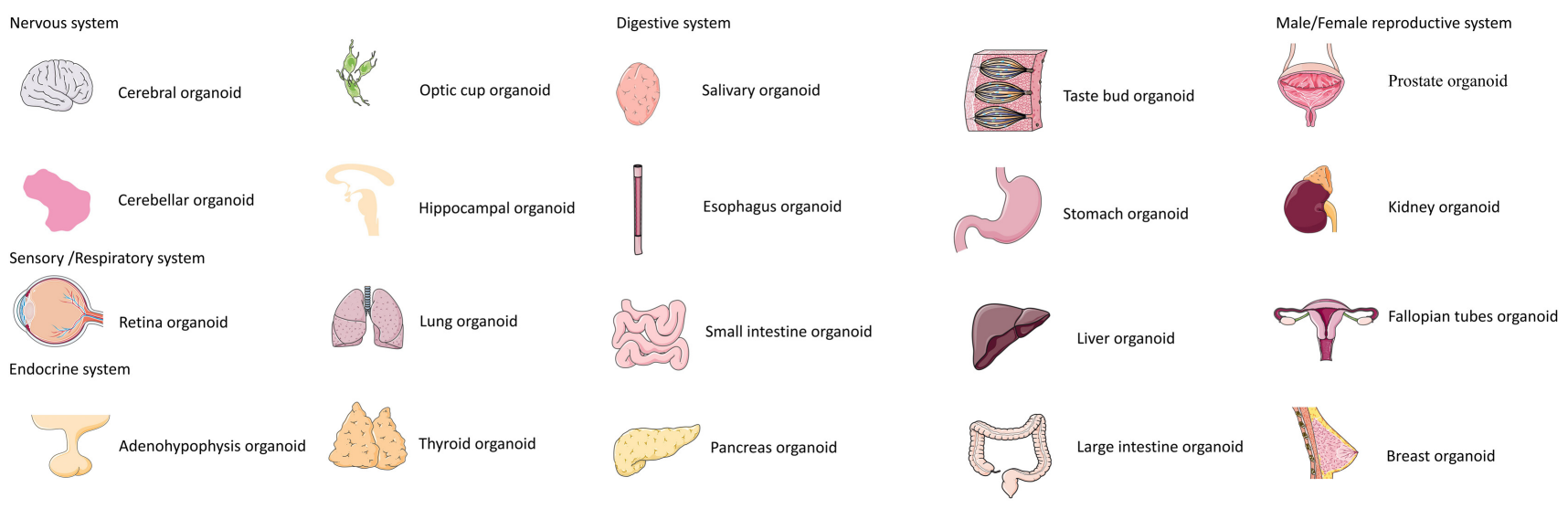

Fig. 1. Organoids have been established of different systems.

mixed human pluripotent stem cells and endothelial cells with smooth muscle cells, which were observed to exhibit a vascular network structure. This model allows researchers to study the whole blood vessel formation in an autonomous manner in vitro. In 2013, Kusuma et al. (17) induced human-derived pluripotent stem cells (hPSC) to differentiate into a microvascular network co-cultured with endothelial cells and pericytes; then they were transplanted into immunodeficient mice. It is noteworthy that the microvascular network was integrated with the host vasculature to build a functional blood system. It is challenging to simulate the human vascular network, since it is difficult to compose a vascular chimera model between the graft of human and mouse. On the other hand, for species differences, the model cannot effectively indicate the actual effect on humans. In 2014, Samuel et al. (18) cocultured hPSC, endothelial cells and mouse-derived mesenchymal progenitor cells to generate functional blood vessels. However, it could only survive about 28 days, so it is difficult to achieve long-term research in vitro. In 2015, Chan et al. (19) transplanted the 3D vascular network via hPSC into type 1 diabetes mellitus mice to mitigate the symptoms (e.g., insufficient or interrupted blood flow). The mentioned symptoms lead to a series of malfunctions for ischemia and hypoxia attributed to diabetic vascular disease though symptoms could be mitigated to some extent after transplantation. This is another major progress in bioengineering and translational medicine for vascularized organoids following the hepatic vascular network model. In 2016, Samuel et al. (20) induced the differentiation of human-derived hPSCs. With the use of tissue engineering technologies, they successfully built a functional microvascular network in immunodeficient mice that could last for nearly one year, thereby presenting a malleable technology to construct anastomosis between artificial blood vessels and host blood vessels. Until 2019, Wimmer et al. (21) transplanted the differentiated microvascular network into immunodeficient mice to form the first vascular organoid. The construction of microvascular networks finally emerged to the vascular organoids. Regardless of the field of organoids, tissue engineering, or translational medicine, this model eliminated the bias of organoids to some extents, and the consensus of the prospects of organoids would be broadened to form functional microcirculation tissues (Fig. 2).

\section{Phenotypic Characteristics of Vascular Organoids}

Coated by Type I collagen matrigel, cytokines and small molecules related to signal transduction facilitated the formation of vascular organoids (Table 1). On the whole, they were surrounded by CD31+, and VE-cadherin were typical molecular markers of endothelial cells, allowing for distinguishing hematopoietic cells that exhibited characteristic phenotype. Smooth muscle actin, recognized as a marker of myoblast, is a common marker for vascular smooth muscle cells and pericytes, identical to plateletderived growth factor receptor. Likewise, the vascular organoids express different phenotypic markers, respectively. For instance, the vascular kidney organoids confirmed that Wilms' tumor suppressor-1 and Lectin Lotus Tetrachlorella appeared. Specific to the liver organoids with vascularization, the special markers consisted of $\mathrm{ZO1}$, ALB and CK8/18 (22). Furthermore, the pancreas was taken as an example, the characteristic proteins (e.g., dipeptidyl peptidase 4) increased drastically after making a joint with blood vessels (23). 

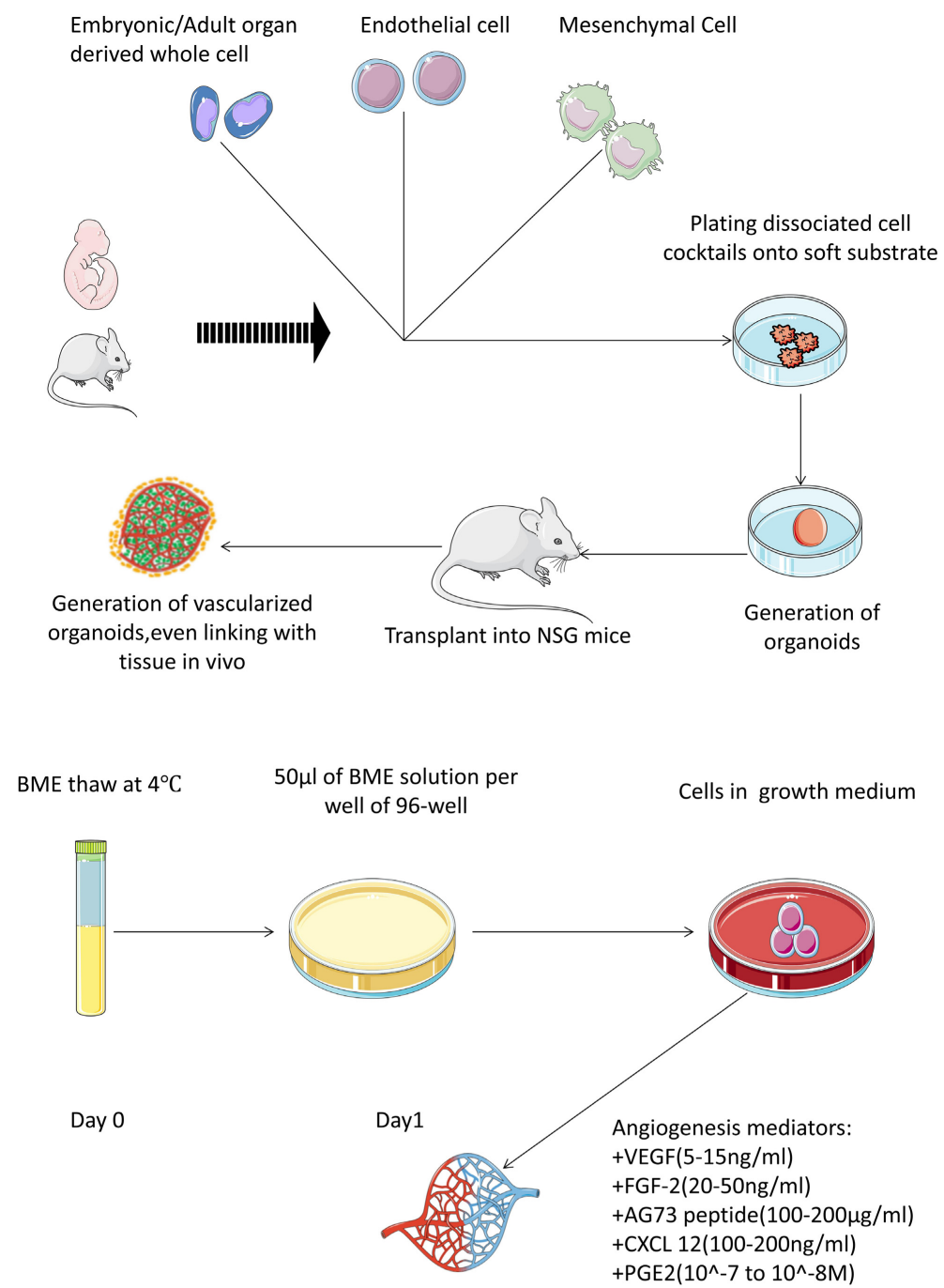

Visualized well-formed blood tube networks after 4-6 hours

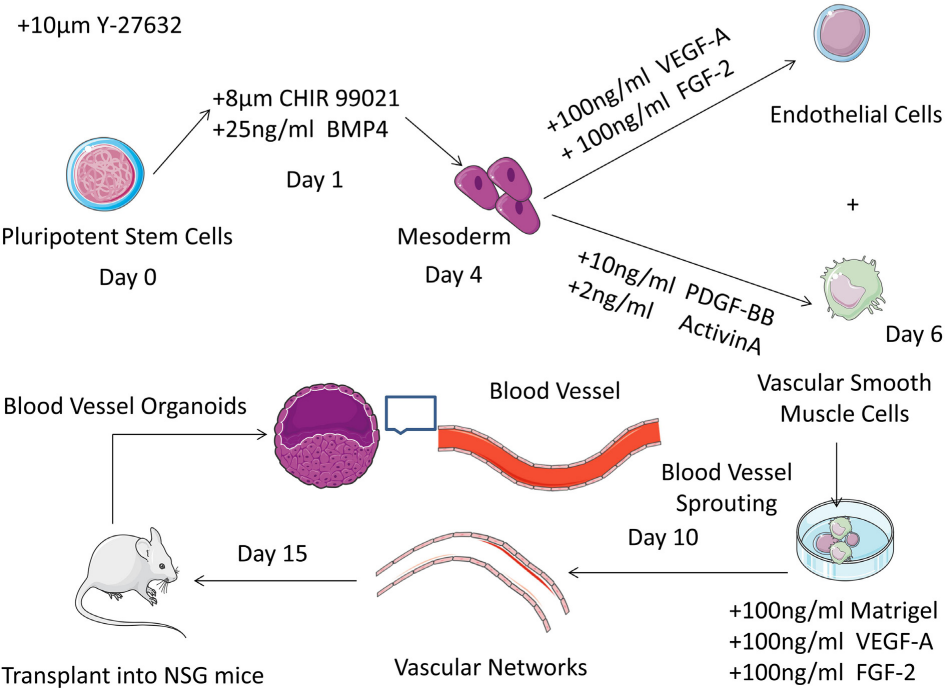

Fig. 2. The procedures of vascular organoids. Co-culturing with embryonic or adult stem cells, endothelial cells and mesenchymal cells, vascular organoids are generated after transplantation (top); On some occasions where there are urgent for the vascular networks, it can be constituded well ex vivo following the steps (medium); As for diseases, blood vessels organoids are masterpieces, in addition to some cytokines and small molecules to form the stem cells niche, it can be generated (bottom). 
Table 1. Function and concentration of supplyments such as cytokines and small molecules in vascular organoids

\begin{tabular}{|c|c|c|}
\hline $\begin{array}{l}\text { Cytokines/small } \\
\text { molecules }\end{array}$ & Function & Concentration \\
\hline Y-27632 & $\begin{array}{l}\text { 1. Rho-related coiled-coil formation protein kinase inhibitors can effectively promote the hPSC } \\
\text { aggreation to enrich cells collection }\end{array}$ & $50 \mu \mathrm{M}$ \\
\hline CHIR99021 & $\begin{array}{l}\text { 1. Potent and highly selective inhibitor of glycogen synthase kinase } 3 \text {; allows formation of } \\
\text { extended pluripotent stem cells }\end{array}$ & $12 \mu \mathrm{M}$ \\
\hline BMP-4 & $\begin{array}{l}\text { 1. Transforming growth factor-beta superfamily ligand that is widely expressed from early } \\
\text { embryogenesis through adulthood } \\
\text { 2. It plays an important role in mesenchyme formation, epidermal determination and the } \\
\text { development of multiple organs. the heterodimers can induce the formation of mesoderm }\end{array}$ & $30 \mathrm{ng} / \mathrm{ml}$ \\
\hline VEGF-A & $\begin{array}{l}\text { 1. A potent mediator of both angiogenesis in the fetus and adult } \\
\text { 2. It is required during embryogenesis to regulate the proliferation, migration, and survival } \\
\text { of endothelial cells }\end{array}$ & $100 \mathrm{ng} / \mathrm{ml}$ \\
\hline FGF-2 & $\begin{array}{l}\text { 1. A member of the FGF superfamily of mitogenic proteins } \\
\text { 2. It stimulates proliferation of all cells of mesodermal origin as well as many cells of } \\
\text { ectodermal, and endodermal origin } \\
\text { 3. It participates in the development of cell proliferation and angiogenesis in vivo }\end{array}$ & $100 \mathrm{ng} / \mathrm{ml}$ \\
\hline PDGF-BB & $\begin{array}{l}\text { 1. PDGF isoforms are potent mitogens for connective tissue cells } \\
\text { 2. It plays an important role in neuron survival and regeneration, and in mediation of glial } \\
\text { cell proliferation and differentiation }\end{array}$ & $1 \sim 10 \mathrm{ng} / \mathrm{ml}$ \\
\hline Activin a & 1. Tumor growth factor-beta inhibitor, involved in the biological processes of hematopoiesis & $1 \sim 10 \mathrm{ng} / \mathrm{ml}$ \\
\hline SB431542 & $\begin{array}{l}\text { 1. Potent and selective inhibitor of the transforming growth factor- } \beta \text { type I receptor/ALK5, } \\
\text { stimulates proliferation and differentiation of ESC-derived endothelial cells }\end{array}$ & $50 \mathrm{nM}$ \\
\hline SB203580 & $\begin{array}{l}\text { 1. Selective inhibitor of p38 MAPK, essential component of medium for maintaining stem cells } \\
\text { in naive pluripotent state }\end{array}$ & $100 \mathrm{nM}$ \\
\hline SP600125 & $\begin{array}{l}\text { 1. Selective JNK inhibitor, competitively and reversibly inhibits JNK1, } 2 \text { and } 3 \text {, essential } \\
\text { component of medium for maintaining stem cells in naive pluripotent state }\end{array}$ & $50 \mathrm{nM}$ \\
\hline
\end{tabular}

\section{The Potential Applications of Vascular Organoids}

Since organoids and host organs have established connections via blood vessels, a range of applications of functional organoids with advance can be explored. Here are the following examples. (1) Mechanism, we can discuss how the procedure of the corresponding organs' development. (2) Pathology, it is possible to study rare vascular diseases under the model, no matter which the primary disease or secondary disease. (3) Exogenous substances, drugs may affect the pathophysiology of organoid by the blood vessel. In summary, the advance and applications of vascularized organoids from different organs are presented below.

\section{The Vascular Kidney Organoids}

Specially, Kidney organoids derive from a mesodermal progenitor containing stromal compartments and the vascular network. Nephron progenitor cells can produce the angioblasts, which means the functional kidney organoids faster than others in theory (24). However, the advantages of histology and embryology are not enough to generate vascularized renal organoids (vRO), therefore, Takebe et al. (22) co-cultured endotheliocytes with mesenchymal stem cells, and then transplanted it into the mice generated microstructure of kidney organoids. It is noteworthy that blood was filled with the capillary network at day 28 , closely related to glomerular vascularization, tissue complexity and kidney functionalization, thereby proving that it had established a mature microcirculation system.

Besides, the original urine was filtered, depending upon the molecular weight small molecular substances $(10 \mathrm{kD})$, large molecular substances $(200 \mathrm{kD})$ like the corresponding kidney, and entered the renal capsule as well as a primary kidney by microscope, moreover, with the theory "Structure Determining Function", it is a promising model for the analysis and treatment of congenital nephrotic syndrome that the deficiency of renin in podocytes due to the renin-coding gene NPHS1 is mutant, Tanigawa et al. (25) corrected the manifestation after implanting the gene in patients. In addition, Adriamycin, a common anti-tumor drug on the single glomerular structure separated from vRO is screened and found that the pore size of glomerular podocytes and expression level of BFP2, a functional marker decrease with the increased dose of Adriamycin, leading to the leakage of large molecular sub- 
stances, which is an alarming symbol for clinical medication (26).

\section{The Vascular Cardiac Organoids}

Distinguished from the mesoderm kidney, the heart, which originates from the endoderm, exhibited late in the organoid field. Given a birth in the tissue engineering, obviously, it is limited to a single ventricle model merely that lacks the capacity for perfusion (27). As we know that heart is a blood pump, which means the angiogenesis is a essence, so cardiomyocytes, endothelial cells and fibroblasts collectively give birth to the vascular cardiac organoids (vCO) ex vivo, ischemic injury would be attenuated by accelerated angiogenesis after transplantation and integration with the host coronary circulation; besides, combined with $3 \mathrm{D}$ bioprinting collectively leading to a living pump that involves with chambers and large vessel conduits. Meanwhile, the model even can be maintained longer than 6 weeks. Apparently, the masterpiece conveys the notion that it will pave the way for generating increasingly complex structures that could include spatially designated pacemaker cells and an associated conduction system with blood perfusion (28).

It is acknowledged that the vCO exhibits the electrical function and mechanical pump (e.g., the pressure of ventricle beating ranging from 0 to $0.5 \mathrm{mmHg}$ ). Specific to the frequency of beat rates approximately $0.07 \mathrm{~Hz}$, the stroke volume of nearly $14 \mu 1 \%$, suggested the notion of advanced maturation (29). vCO was incubated with investigational compounds (e.g., ticagrelor with aspirin) to determine efficacy and toxicity profiles based on vascularization (30). Looking forward, vCO might act as a testbed for cardiac medical devices and eventually lead to therapeutic tissue grafting to remodel the diseased heart.

\section{The Vascular Liver Organoids}

Blood perfusion, as a site of metabolism and digestion, is vital to the liver as well as kidney and heart. Indeed, blood in the hepatic sinusoid carries the hormone signal to communicate with the adjacent liver cells. Therefore, as inspired by Korzh et al. (31), who found that morphogenetic changes are determined by the exquisite orchestration of signals between endodermal epithelial, mesenchymal and endothelial progenitors before blood perfusion, Huch et al. (32), generating a vascular liver organoids from the specified hepatic cells, and Takebe et al. (33) absorbed on their advantages and designed the liver organoids formation by co-culturing hepatic endoderm cells with endothelial and mesenchymal lineages on three-dimensional structures; in addition, the vascular liver organoids were quickly connected to the blood of the host in 48 hours after being transplanted into the mouse.

The length and the cover area of the blood vessel network (up to 68\%) was increasingly larger than that of cell transplantation (merely 24\%). Angiogenesis underpins metabolism, so functional liver organoids produce 222 metabolites with metabolomics analysis, including liver-specific metabolites (e.g., taurocholic acid). The interaction between mesenchymal cells and hepatocytes may release vascular endothelial growth factor and stimulate the formation of endothelial network, which is critical for the production of albumin and expression of specific enzymes in the liver, as well as the transformation of liver organoids towards more mature functions, consistent with the metabolic capacity of the liver highly. Thus, it can replace the liver to provide a prosperous model for the metabolism of multiple drugs or toxicants (34).

\section{The Vascular Pancreas Organoids}

Besides the liver, the pancreas is a unignorable digestive organ, blood perfusion is necessary for its functions on endocrine and exocrine. In particular, the endocrine function that primarily improves insulin deficiency can address diabetes mellitus. Based on the knowledge, the $\beta$ cells of pancreas were co-cultured with endothelial cells, and the pancreas organoids were quickly perfused by blood flow to give a new life to the $\beta$-cells after transplanting in mice. By the way, the density of the reconstructing pancreatic islets of the microcirculation network, consisting of the basement membrane and endothelial cell that collectively support the $\beta$ cells, was nearly 4.2 times that of the surrounding tissues (35). Blood vessels might be capable of secreting chemokines: Cxcl12 during the early period of pancreatic organoids formation. Moreover, stroma secreting Fgf10 indirectly cross communicated the information with the organoids to create the epithelial signal to make the organoids survive longer.

To assess its function, the formed structure was transplanted into the kidney capsule of a type 1 diabetic mellitus mouse model. By constructing a vascular pancreas organoids, the cover area of blood vessel took up nearly $50 \%$; it is noteworthy that the blood glucose of the mice dropped from $600 \mathrm{mg} / \mathrm{dl}$ to $400 \mathrm{mg} / \mathrm{d}$ sharply, the mice were successfully cured (33). However, contrasted with transplanting the pancreatic cells or mesenchymal cells, the blood glucose of mice fluctuated around $400 \mathrm{mg} / \mathrm{dl}$ some time, and the effects may be delayed due to the failure 
of vascularization $(36,37)$.

\section{The Vascular Brain Organoids}

As the representative of the ectoderm, the emergence of brain organoids attracted great attention as early as 2013 (7). However, there is no exception that an obstacle appears that oxygen and nutrient cannot deliver to the inner-most parts of the model due to the human brain organoids (hBOs) lacking microcirculation. To address the mentioned problem, Mansour et al. (38) formed the vascular brain organoids under the oxygen concentration reduced to $2 \%$, the blood vessels were filled with the whole organoids, both of which produced potentials exhibiting the functional vessel-like organoids structures to promote neuronal maturation. Acevedo et al. (39) transplanted vascularized brain organoids into the skull of mice. Neuronal discharge was monitored on the electrodes, suggesting the successful formation of functional brain organoids. Song et al. (40) analyzed the potential impacts of growth factors on neuronal growth of brain organoids using the model, suggesting that the glucose transporter GLUT-1 was up-regulated after blood nurturing of brain organoids. Notably, the continuous endothelium help maintain the structural and functional integrity of the brain, so vascularization is critical for improving this model for usage.

\section{The Vascular Gastrointestinal Organoids}

Initially, the gastrointestinal organoids were merely induced by epithelial cells, whereas the matrix, the skeleton of connective tissue in the organs, was mainly derived from mesoderm. Thus, the earliest gastrointestinal organoids lacked vascular stroma and mainly simulated the structure. As the first human gastric organoid (hGO), the mesodermal remnants surrounded the epithelial structures to supply for oxygen to form a complete stem cells niche (41). From the perspective of the permeability, human vascular intestine organoids (hIO) were transplanted into immunodeficient mice, a range of the intestine cells were presented (e.g., enterocytes, goblet cells and Paneth cells).

The diameter of hIO increased to $6.72 \mathrm{~mm}$, and a lumen structure could be observed, compared with that before transplantation $(1.75 \mathrm{~mm})$ (42). Characteristics were assigned to the ideal alternative to the treatment of short bowel syndrome attributed to resection of intestinal structures with excessive lesions. Moreover, concerning the considerable microorganisms in the intestine, the hIO could be used to explore the interaction between host organoids and enteroviruses (43). Li et al. (44) infected gastro- enteritis virus using the in vitro cultured hIO, they drew a conclusion that considerable inflammatory factors were upregulated. In brief, with the blood vessels anticipating, the gastrointestinal organoids generated a complex multiline microenvironment functionally.

\section{The Blood Vessel Organoids}

Blood vessels act as the interstitial components of the substantive organs as the top descriptions. More importantly, endothelial cells are directly induced in vitro to form blood vessel organoids (bVO), which are primarily adopted to the study on vascular diseases. Since bVO tends to convey numerous research fields, Wimmer et al. (21) studied the mechanism of the basement membrane thickening of diabetes in bVO where there was diabetic angiopathy. Additionally, the effect of drugs on human vascular physiology remedied the defects of the previous models significantly, similar to the $\gamma$-secretase inhibitor, which could interrupt the phenomenon in the high-glycemic medium by inhibiting the disorder of basement membrane, thereby ensuring their safety and effectiveness and accelerating the pace of clinical trials (45). Besides, the pandemic COVID-19 virus, bVO expresses antiangiotensin converting enzyme II to appear to cause a popular in relative research, Monteil et al. (46) established capillaries organoids that were infected by SARS-CoV-2, meanwhile found it produced progeny virus. Besides, it was an indicator to measure parameters (e.g., maturity and blood vessel function). Therefore, it could be employed to study vascular diseases to illustrate the cerebrovascular atherosclerosis attributed to dyslipidemia.

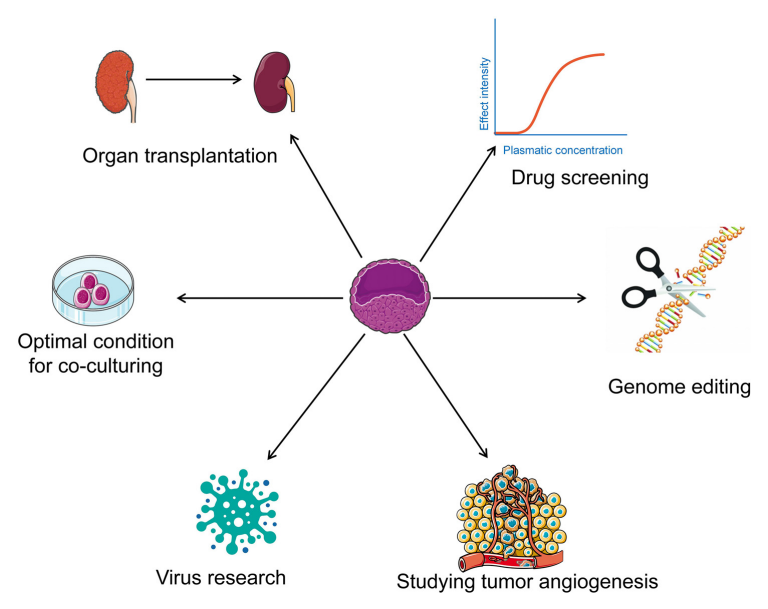

Fig. 3. The application prospects of vascular organoids. 


\section{Perspective and Prospect}

Organoids, corresponding to the viscera function in vitro in part and quickly win the favor of many researchers, however, a lack of stromal elements especially the functional blood vessels, causing the maturity and function a dilemma. With the endothelial cells and co-culture system introduction, vascularization organoids improve the problem significantly. Moreover, functional organoids bring forward to some prospective applications (Fig. 3).

Transplantation refers to one of its remarkable advantages: especially under shortage of donors and long-term use of immunosuppressive agents, the patient's defense system is destroyed inevitably. Applying this model to replace organs or cell transplantation is capable of remodeling functional organs on one hand, and avoiding immune rejection on the other hand (47). Furthermore, it is more suitable for inventing new drugs and personalized treatments for the distribution of active components of medicine varied with blood flow participating in. The combination of CRISP-Cas9 with it can correct mutated genes by editing technologies and study the effects of specific mutations on the development and progress of diseases. It is undoubtedly that angiogenesis is critical for tumors. Transporting nutrients and the excretion of metabolic wastes should rely on the blood vessels, so it acts as a vital element to maintain the growth of tumors (48). Considerable studies on infectious diseases also require the functional models in vitro; for instance, COVID-2019 affects multiple organs, Zika virus aims at the brain and Norovirus target at the intestine, the blood flow affects the distribution of pathogen cannot be underestimated. In addition, as the microenvironmental components, vascularization attached to the different organs demands on matching matrix stiffness of the culture system, so we are urged to improve the existing culture system.

Accordingly, it is essentially practical for the prospect of vascularized organoids to improve the multilineages communication to confirm the impact on the model with vasculature in detail. In other words, vascularized organoids can reproduce the near-native function of the solid organ, as well as creating a highly similar internal environment for both fundamental and biomedical research. The rapid progress of vascular organoids promises potential prospects into developmental biology and paves new ways towards curing human disease and regenerative medicine.

\section{Discussion}

Since the generation of organoids, carrying out indivi- dual therapy, synthetizing novel drugs and exploring the mechanism of resistance and metastasis in disease are considered the major concerns of researches. The existing research hotspot primarily focuses on the isolated organoid models, from morphological changes to the drug screening. They fail to capture the spatial dynamic changes between vascularized organoids and the corresponding tissues, leading to a frustrating phenomenon of the mechanism research in-depth and clinical applications. Besides, the size of the organoid differs by orders of magnitude from that of the resource organs in terms of structure. Thus, many laboratories have been in a dilemma of how to optimize the model to deliver nutrients to better induce its differentiation and proliferation to form a resemble alternative, a prevailing notion occurred that it is impractical to recapitulate the interactions closely between organoids and blood vessels in vitro (49).

It is known that blood vessels usually serve to promote signal transduction between cell-cells and cell-matrix, completing the regulation work which is critical to the isolated and disordered cell in the early stage of reaggregation to achieve the goal that re-growing a vascular organoid is similar to corresponding organs. As a result, vascular endothelial cells are essential components. Besides, major diseases (e.g., heart attack, diabetes or cancer) are closely related to the blood vessels dysfunction. However, it is an unstable and malfunctional model, in addition, fitting together with the host and maintaining the long-term culture, the related research remains in infancy.

Over the past few years, the ability of cell transplantation to repair damaged tissues is limited, and mesenchymal components especially the vessels are introduced to make them closer to the corresponding tissues for function and maturity (50). As vast improvements on the technology are still required to achieve this goals, the alternative can potentially tackle down many other models' limitations while maintaining in vitro accessibility and scalability. In brief, this study envisions that the field may see this type of application and many others in the future.

\section{Acknowledgments}

None.

\section{Potential Conflict of Interest}

The authors have no conflicting financial interest.

\section{Author Contributions}

Conceptualization: Jin $\mathrm{Yu}$

Investigation: Jin $\mathrm{Yu}$

Resources: Jin $\mathrm{Yu}$ 
Supervision: Jin $\mathrm{Yu}$

Writing - original draft: Jin $\mathrm{Yu}$

Writing - review \& editing: Jin Yu

\section{References}

1. Weiss P, Taylor AC. Reconstitution of complete organs from single-cell suspensions of chick embryos in advanced stages of differentiation. Proc Natl Acad Sci U S A 1960;46: $1177-1185$

2. Cherry AB, Daley GQ. Reprogramming cellular identity for regenerative medicine. Cell 2012;148:1110-1122

3. Lancaster MA, Knoblich JA. Organogenesis in a dish: modeling development and disease using organoid technologies. Science 2014;345:1247125

4. Ding BS, Nolan DJ, Butler JM, James D, Babazadeh AO, Rosenwaks Z, Mittal V, Kobayashi H, Shido K, Lyden D, Sato TN, Rabbany SY, Rafii S. Inductive angiocrine signals from sinusoidal endothelium are required for liver regeneration. Nature 2010;468:310-315

5. Levenberg S, Rouwkema J, Macdonald M, Garfein ES, Kohane DS, Darland DC, Marini R, van Blitterswijk CA, Mulligan RC, D'Amore PA, Langer R. Engineering vascularized skeletal muscle tissue. Nat Biotechnol 2005;23:879884

6. Eiraku M, Takata N, Ishibashi H, Kawada M, Sakakura E, Okuda S, Sekiguchi K, Adachi T, Sasai Y. Self-organizing optic-cup morphogenesis in three-dimensional culture. Nature 2011;472:51-56

7. Lancaster MA, Renner M, Martin CA, Wenzel D, Bicknell LS, Hurles ME, Homfray T, Penninger JM, Jackson AP, Knoblich JA. Cerebral organoids model human brain development and microcephaly. Nature 2013;501:373-379

8. Muguruma K, Nishiyama A, Kawakami H, Hashimoto K, Sasai Y. Self-organization of polarized cerebellar tissue in 3D culture of human pluripotent stem cells. Cell Rep 2015; 10:537-550

9. Sakaguchi H, Kadoshima T, Soen M, Narii N, Ishida Y, Ohgushi M, Takahashi J, Eiraku M, Sasai Y. Generation of functional hippocampal neurons from self-organizing human embryonic stem cell-derived dorsomedial telencephalic tissue. Nat Commun 2015;6:8896

10. Wong AP, Bear CE, Chin S, Pasceri P, Thompson TO, Huan LJ, Ratjen F, Ellis J, Rossant J. Directed differentiation of human pluripotent stem cells into mature airway epithelia expressing functional CFTR protein. Nat Biotechnol 2012;30:876-882

11. Dye BR, Hill DR, Ferguson MA, Tsai YH, Nagy MS, Dyal R, Wells JM, Mayhew CN, Nattiv R, Klein OD, White ES, Deutsch GH, Spence JR. In vitro generation of human pluripotent stem cell derived lung organoids. Elife 2015;4: e05098

12. Dianat N, Dubois-Pot-Schneider H, Steichen C, Desterke C, Leclerc P, Raveux A, Combettes L, Weber A, Corlu A, Dubart-Kupperschmitt A. Generation of functional chol- angiocyte-like cells from human pluripotent stem cells and HepaRG cells. Hepatology 2014;60:700-714

13. Ogawa M, Ogawa S, Bear CE, Ahmadi S, Chin S, Li B, Grompe M, Keller G, Kamath BM, Ghanekar A. Directed differentiation of cholangiocytes from human pluripotent stem cells. Nat Biotechnol 2015;33:853-861

14. Sato T, Vries RG, Snippert HJ, van de Wetering $M$, Barker $\mathrm{N}$, Stange DE, van Es JH, Abo A, Kujala P, Peters PJ, Clevers H. Single Lgr5 stem cells build crypt-villus structures in vitro without a mesenchymal niche. Nature 2009; 459:262-265

15. Baptista PM, Siddiqui MM, Lozier G, Rodriguez SR, Atala A, Soker S. The use of whole organ decellularization for the generation of a vascularized liver organoid. Hepatology 2011;53:604-617

16. Quint C, Arief M, Muto A, Dardik A, Niklason LE. Allogeneic human tissue-engineered blood vessel. J Vasc Surg 2012;55:790-798

17. Kusuma S, Shen YI, Hanjaya-Putra D, Mali P, Cheng L, Gerecht S. Self-organized vascular networks from human pluripotent stem cells in a synthetic matrix. Proc Natl Acad Sci U S A 2013;110:12601-12606

18. Samuel R, Daheron L, Liao S, Vardam T, Kamoun WS, Batista A, Buecker C, Schäfer R, Han X, Au P, Scadden DT, Duda DG, Fukumura D, Jain RK. Generation of functionally competent and durable engineered blood vessels from human induced pluripotent stem cells. Proc Natl Acad Sci U S A 2013;110:12774-12779

19. Chan XY, Black R, Dickerman K, Federico J, Lévesque M, Mumm J, Gerecht S. Three-dimensional vascular network assembly from diabetic patient-derived induced pluripotent stem cells. Arterioscler Thromb Vasc Biol 2015;35:26772685

20. Samuel R, Duda DG, Fukumura D, Jain RK. Vascular diseases await translation of blood vessels engineered from stem cells. Sci Transl Med 2015;7:309rv6

21. Wimmer RA, Leopoldi A, Aichinger M, Kerjaschki D, Penninger JM. Generation of blood vessel organoids from human pluripotent stem cells. Nat Protoc 2019;14:30823100

22. Takebe T, Enomura M, Yoshizawa E, Kimura M, Koike H, Ueno Y, Matsuzaki T, Yamazaki T, Toyohara T, Osafune K, Nakauchi H, Yoshikawa HY, Taniguchi H. Vascularized and complex organ buds from diverse tissues via mesenchymal cell-driven condensation. Cell Stem Cell 2015;16: 556-565

23. Kroon E, Martinson LA, Kadoya K, Bang AG, Kelly OG, Eliazer S, Young H, Richardson M, Smart NG, Cunningham J, Agulnick AD, D'Amour KA, Carpenter MK, Baetge EE. Pancreatic endoderm derived from human embryonic stem cells generates glucose-responsive insulin-secreting cells in vivo. Nat Biotechnol 2008;26:443-452

24. Homan KA, Gupta N, Kroll KT, Kolesky DB, Skylar-Scott M, Miyoshi T, Mau D, Valerius MT, Ferrante T, Bonventre JV, Lewis JA, Morizane R. Flow-enhanced vascularization and maturation of kidney organoids in vitro. Nat Methods 


\section{9;16:255-262}

25. Tanigawa $S$, Islam $M$, Sharmin $S$, Naganuma $H$, Yoshimura Y, Haque F, Era T, Nakazato H, Nakanishi K, Sakuma T, Yamamoto T, Kurihara H, Taguchi A, Nishinakamura R. Organoids from nephrotic disease-derived iPSCs identify impaired NEPHRIN localization and slit diaphragm formation in kidney podocytes. Stem Cell Reports 2018;11: 727-740

26. Cruz NM, Song X, Czerniecki SM, Gulieva RE, Churchill AJ, Kim YK, Winston K, Tran LM, Diaz MA, Fu H, Finn LS, Pei Y, Himmelfarb J, Freedman BS. Organoid cystogenesis reveals a critical role of microenvironment in human polycystic kidney disease. Nat Mater 2017;16:11121119

27. Leonard A, Bertero A, Powers JD, Beussman KM, Bhandari S, Regnier M, Murry CE, Sniadecki NJ. Afterload promotes maturation of human induced pluripotent stem cell derived cardiomyocytes in engineered heart tissues. J Mol Cell Cardiol 2018;118:147-158

28. Kupfer ME, Lin WH, Ravikumar V, Qiu K, Wang L, Gao L, Bhuiyan DB, Lenz M, Ai J, Mahutga RR, Townsend D, Zhang J, McAlpine MC, Tolkacheva EG, Ogle BM. In situ expansion, differentiation, and electromechanical coupling of human cardiac muscle in a 3D bioprinted, chambered organoid. Circ Res 2020;127:207-224

29. Sekine H, Shimizu T, Hobo K, Sekiya S, Yang J, Yamato M, Kurosawa H, Kobayashi E, Okano T. Endothelial cell coculture within tissue-engineered cardiomyocyte sheets enhances neovascularization and improves cardiac function of ischemic hearts. Circulation 2008;118(14 Suppl):S145S152

30. Becker RC, Sadayappan S. Designing human in vitro models for drug development. J Am Coll Cardiol 2020;75:587589

31. Korzh S, Pan X, Garcia-Lecea M, Winata CL, Pan X, Wohland T, Korzh V, Gong Z. Requirement of vasculogenesis and blood circulation in late stages of liver growth in zebrafish. BMC Dev Biol 2008;8:84

32. Huch M, Dorrell C, Boj SF, van Es JH, Li VS, van de Wetering M, Sato T, Hamer K, Sasaki N, Finegold MJ, Haft A, Vries RG, Grompe M, Clevers H. In vitro expansion of single $\mathrm{Lgr}^{+}$liver stem cells induced by Wntdriven regeneration. Nature 2013;494:247-250

33. Takebe T, Sekine K, Enomura $M$, Koike H, Kimura $M$, Ogaeri T, Zhang RR, Ueno Y, Zheng YW, Koike N, Aoyama $\mathrm{S}$, Adachi Y, Taniguchi H. Vascularized and functional human liver from an iPSC-derived organ bud transplant. Nature 2013;499:481-484

34. Asai A, Aihara E, Watson C, Mourya R, Mizuochi T, Shivakumar P, Phelan K, Mayhew C, Helmrath M, Takebe T, Wells J, Bezerra JA. Paracrine signals regulate human liver organoid maturation from induced pluripotent stem cells. Development 2017;144:1056-1064

35. Rodríguez-Seguel E, Mah N, Naumann H, Pongrac IM, Cerdá-Esteban N, Fontaine JF, Wang Y, Chen W, AndradeNavarro MA, Spagnoli FM. Mutually exclusive signaling signatures define the hepatic and pancreatic progenitor cell lineage divergence. Genes Dev 2013;27:1932-1946

36. Grigoryan T, Wend P, Klaus A, Birchmeier W. Deciphering the function of canonical Wnt signals in development and disease: conditional loss- and gain-of-function mutations of beta-catenin in mice. Genes Dev 2008;22:2308-2341

37. Puri S, Hebrok M. Cellular plasticity within the pancreas-lessons learned from development. Dev Cell 2010;18:342356

38. Mansour AA, Gonçalves JT, Bloyd CW, Li H, Fernandes S, Quang D, Johnston S, Parylak SL, Jin X, Gage FH. An in vivo model of functional and vascularized human brain organoids. Nat Biotechnol 2018;36:432-441

39. Acevedo LM, Lindquist JN, Walsh BM, Sia P, Cimadamore F, Chen C, Denzel M, Pernia CD, Ranscht B, Terskikh A, Snyder EY, Cheresh DA. hESC differentiation toward an autonomic neuronal cell fate depends on distinct cues from the co-patterning vasculature. Stem Cell Reports 2015;4: 1075-1088

40. Song L, Yuan X, Jones Z, Griffin K, Zhou Y, Ma T, Li Y. Assembly of human stem cell-derived cortical spheroids and vascular spheroids to model 3-D brain-like tissues. Sci Rep 2019;9:5977

41. McCracken KW, Catá EM, Crawford CM, Sinagoga KL, Schumacher M, Rockich BE, Tsai YH, Mayhew CN, Spence JR, Zavros Y, Wells JM. Modelling human development and disease in pluripotent stem-cell-derived gastric organoids. Nature 2014;516:400-404

42. Watson CL, Mahe MM, Múnera J, Howell JC, Sundaram N, Poling HM, Schweitzer JI, Vallance JE, Mayhew CN, Sun Y, Grabowski G, Finkbeiner SR, Spence JR, Shroyer NF, Wells JM, Helmrath MA. An in vivo model of human small intestine using pluripotent stem cells. Nat Med 2014; 20:1310-1314

43. Grün D, Lyubimova A, Kester L, Wiebrands K, Basak O, Sasaki N, Clevers H, van Oudenaarden A. Single-cell messenger RNA sequencing reveals rare intestinal cell types. Nature 2015;525:251-255

44. Li Y, Yang N, Chen J, Huang X, Zhang N, Yang S, Liu G, Liu GL. Next-generation porcine intestinal organoids: an apical-out organoid model for swine enteric virus infection and immune response investigations. J Virology 2020;94:e01006-20

45. Soler MJ, Riera M, Batlle D. New experimental models of diabetic nephropathy in mice models of type 2 diabetes: efforts to replicate human nephropathy. Exp Diabetes Res 2012;2012:616313

46. Monteil V, Kwon H, Prado P, Hagelkrüys A, Wimmer RA, Stahl M, Leopoldi A, Garreta E, Hurtado Del Pozo C, Prosper F, Romero JP, Wirnsberger G, Zhang H, Slutsky AS, Conder R, Montserrat N, Mirazimi A, Penninger JM. Inhibition of SARS-CoV-2 infections in engineered human tissues using clinical-grade soluble human ACE2. Cell 2020;181:905-913.e7

47. Lindvall O. Clinical translation of stem cell transplantation in Parkinson's disease. J Intern Med 2016;279:30-40 
48. Sobrino A, Phan DT, Datta R, Wang X, Hachey SJ, Romero-López M, Gratton E, Lee AP, George SC, Hughes CC. 3D microtumors in vitro supported by perfused vascular networks. Sci Rep 2016;6:31589

49. Li M, Izpisua Belmonte JC. Organoids- preclinical models of human disease. N Engl J Med 2019;380:569-579

50. Kretzschmar K, Clevers H. Organoids: modeling development and the stem cell niche in a dish. Dev Cell 2016;38: 590-600 